\title{
Suitability Evaluation of Urban Kangyang in Heilongjiang Province
}

\author{
Wei Wang ${ }^{1}$, Chuanwang Pei ${ }^{1, *}$ \\ ${ }^{1}$ Harbin University of Commerce, Harbin, Heilongjiang, China
}

\begin{abstract}
With the change of the elderly's demand for pension, Kangyang has become a new way of providing for the aged. In order to study the suitability of Kangyang various cities in Heilongjiang Province, based on the relevant scholars' research on different types of Kangyang, the basic framework of evaluation system was established by combing the four elements of ecology, humanity, people's livelihood and medical treatment. 25 indexes were selected as evaluation indexes, and the evaluation was conducted by entropy weight - TOPSIS method. The results show that Yichun is the most suitable city for health care, Qiqihar and Suihua need to strengthen construction in all aspects, and other cities have their own advantages. Therefore, the city needs to strengthen different aspects of construction according to its own actual situation, so as to enhance the comprehensive strength of the suitability of health care.
\end{abstract}

\section{Introduction}

Since the 1990s, China's aging problem has been increasing, and the related pension issues have been constantly explored and discussed. By the end of 2019, there are 253.88 million people aged 60 and above, accounting for $18.1 \%$ of the total population in China. It is expected that the population will continue to increase to about $34.1 \%$ by 2050 . It can be seen that the research on the pension problem and the development of the elderly market have practical significance. With the enrichment of material, the importance of physical and mental health becomes particularly important. The 2016 Healthy China 2030 Planning Outline proposed that by 2030, the health industry will become the pillar industry of the national economy. Health care can not only provide more diversified ways of old-age care for the elderly to meet the needs of different elderly people, but also can develop the silver hair economy and promote the development of local economy. With the development of Kangyang industry, the pressure of the elderly pension needs has been alleviated, and the quality of life of the elderly has been improved.

\section{Research summary}

\subsection{Research status at home and abroad}

Annual Report on Kangyang Industry of China (2017) pointed out that "Kangyang" is an inclusive concept, covering a wide range: health care can be a sustained and systematic behavioral activity, but also a short-term, targeted and single health and medical behavior. From the perspective of life, Kanyang should take into account the three dimensions of life: the length of life; the abundance of spiritual level; the degree of freedom of life, which is the international index system used to describe the quality of life. The core function of Kangyang is to maximize the length, abundance and freedom of life.Kangyang originated in Germany and prevail in the United States, Japan, South Korea and other developed countries ${ }^{[1]}$. It mainly includes forest Kangyang, hot spring Kangyang, bathing beach, Kneipp therapy. There are few researches on the evaluation of Kangyang in China, most of them are about forest Kangyang. First of all, the selection of safe areas without natural disasters should be considered ${ }^{[2]}$. There are fewer natural disasters in Heilongjiang region, and the frequency of sudden disasters such as debris flow, landslide, earthquake and typhoon is very low, which is conducive to the development of health care industry. Secondly, climate, resources, medical treatment and traffic conditions should be considered ${ }^{[3-5]}$. Finally, different methods can be used to evaluate suitability, such as: analytic hierarchy process (AHP) to determine the weight by issuing questionnaires and expert consultation scoring ${ }^{[6,7]}$; and the central model method based on $\mathrm{SNA}^{[8]}$.

\subsection{Current situation of Kangyang development in Heilongjiang province}

Heilongjiang Province is located in the northeast corner of China, with a vast area and rich natural and cultural resources, which is conducive to the development of health care industry. There are many different types of tourism resources in Heilongjiang Province, so we should focus on the establishment of tourism scenic spots integrating Kangyang elements. The development of

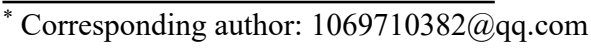


Kangyang tourism industry in Heilongiiang Province has initially formed a scale. After the development in recent years, many elderly people choose to experience the service of living in Mehe. Wudalianchi scenic spot is also famous in the world. With the advantages of topography, Heilongjiang Province has superior forest resources and geothermal resources under the influence of temperate continental monsoon climate, which is conducive to the steady development of forest Kangyang. In 2016, the government put forward the guiding opinions on accelerating the forest Kangyang industry to promote the forestry economic development of Heilongjiang Province. At the same time, Harbin has built the first medical and nursing community in the three northeastern provinces, Xingyuan international health care center, which provides the public with five in one health care services including provide for the aged, medical care, health, nursing and enjoyment, marking the beginning of the combination of medical care and nursing in northern China.

In order to study the development of the suitability of health care in cities of Heilongjiang Province, this paper selects 12 prefecture level cities as the research individuals. In the selection of general indicators, it adds the humanistic construction index which pays attention to the spiritual care of the elderly ${ }^{[9]}$. In order to avoid the error caused by subjective factors, the evaluation model based on entropy weight - TOPSIS is is selected to rank, hoping to provide effective guidance for the development of health care industry in cities.

\section{Index selection}

For the selection of the city, we should consider the actual needs of the audience. Through the study of relevant literature and actual situation, people's demand for 'Kang' is mainly reflected in the attention to medical conditions. Medical facilities play a role in protecting personal health. The evaluation system can be constructed through the number of hospitals, the professional degree of employees, and the investment in medical treatment. The demand for 'Yang' is mainly reflected in the environment and people's livelihood, good ecological environment and convenient urban construction are conducive to meet the elderly group's desire to improve the quality of health and pension. Due to the decline of the physical quality of the elderly, the requirements for the environment are gradually improved, and the temperature, air, greening and other aspects need to be considered; at the same time, the income and travel ability of the elderly are gradually reduced, and they are in a disadvantaged position. Therefore, it is the focus of the investigation of people's livelihood construction to inquire into the local consumption capacity, whether the elderly can afford it, and whether the traffic conditions are convenient. In addition, with the increasing demand for spiritual and cultural pursuits and psychological comfort of the elderly, this paper believes that the local cultural construction is also an important indicator to investigate the suitability of Kangyang. These factors affect the feelings of the local people from all aspects of life. Therefore, based on the reference of relevant literature, the index system for evaluating the suitability of the Kangyang system in Table 1 is constructed.

Table1. Evaluation index system of Kangyang suitability

\begin{tabular}{|c|c|}
\hline $\begin{array}{l}\text { Classification } \\
\text { indexes }\end{array}$ & Basic indexes \\
\hline \multirow{6}{*}{$\begin{array}{l}\text { Ecological } \\
\text { construction }\end{array}$} & $\begin{array}{l}\text { Per capita park green space (square } \\
\text { meters / person) }\end{array}$ \\
\hline & $\begin{array}{l}\text { Per capita urban garden and green } \\
\text { space area (square meters / person) }\end{array}$ \\
\hline & $\begin{array}{c}\text { Green coverage rate in built-up areas } \\
(\%)\end{array}$ \\
\hline & $\begin{array}{c}\text { Per capita total water resources } \\
(10,000 \text { cubic meters / person })\end{array}$ \\
\hline & $\begin{array}{c}\text { Days of annual average temperature } \\
15-25 \text { degrees (days) }\end{array}$ \\
\hline & $\begin{array}{l}\text { Days with ambient air quality index } \\
\text { (AQI) less than 50(days) }\end{array}$ \\
\hline \multirow{7}{*}{$\begin{array}{l}\text { Cultural } \\
\text { construction }\end{array}$} & $\begin{array}{c}\text { Per capita public library (per person / } \\
10,000 \text { people) }\end{array}$ \\
\hline & $\begin{array}{c}\text { Per capita museums (per person / } \\
10,000 \text { people) }\end{array}$ \\
\hline & $\begin{array}{l}\text { Per capita mass art center and cultural } \\
\text { center (per person } / 10,000 \text { people) }\end{array}$ \\
\hline & $\begin{array}{l}\text { Per capita cultural station (per person } \\
\qquad / 10,000 \text { people) }\end{array}$ \\
\hline & $\begin{array}{c}\text { Per capita total collections of public } \\
\text { libraries (1000 volumes / 10,000 } \\
\text { people) }\end{array}$ \\
\hline & $\begin{array}{c}\text { The library organizes various } \\
\text { activities for readers (times/10,000 } \\
\text { people) }\end{array}$ \\
\hline & $\begin{array}{c}\text { Average floor area of libraries ( } 1000 \\
\text { square metres / piece) }\end{array}$ \\
\hline \multirow{7}{*}{$\begin{array}{l}\text { Construction of } \\
\text { people's livelihood }\end{array}$} & Per capita disposable income (yuan) \\
\hline & $\begin{array}{l}\text { Per capita social security and } \\
\text { employment expenditure (yuan / } \\
\text { person) }\end{array}$ \\
\hline & $\begin{array}{l}\text { Per capita expenditure on science and } \\
\text { technology (yuan / 10,000 people) }\end{array}$ \\
\hline & $\begin{array}{c}\text { Public transport vehicles per 10,000 } \\
\text { people number of (vehicles) }\end{array}$ \\
\hline & $\begin{array}{c}\text { Number of taxis per } 10000 \text { people } \\
\text { (taxis) }\end{array}$ \\
\hline & $\begin{array}{c}\text { Per capita urban road area (square } \\
\text { meters / person) }\end{array}$ \\
\hline & $\begin{array}{c}\text { Number of street lamps (lights / } \\
10,000 \text { square meters) }\end{array}$ \\
\hline \multirow{5}{*}{$\begin{array}{l}\text { Construction of } \\
\text { medical }\end{array}$} & $\begin{array}{c}\text { Number of hospitals per } 10,000 \\
\text { people (hospitals) }\end{array}$ \\
\hline & $\begin{array}{l}\text { Number of hospital beds per } 10,000 \\
\text { people (hospital beds) }\end{array}$ \\
\hline & $\begin{array}{c}\text { Medical practitioners (assistant) per } \\
10,000 \text { people(number) }\end{array}$ \\
\hline & $\begin{array}{l}\text { Registered nurse, nurse (person) per } \\
10,000 \text { people(number) }\end{array}$ \\
\hline & $\begin{array}{l}\text { Medical and health care and family } \\
\text { planning (yuan/person) }\end{array}$ \\
\hline
\end{tabular}

\section{Based on entropy weight - topsis model}

Entropy weight method is a method to determine the objective weight according to the index value, and to obtain the comprehensive index value by considering the 
information provided by each index. TOPSIS method, that is, the ranking method of approximate ideal solutions, takes the relative closeness degree determined by the distance between the evaluation object and the positive and negative ideal solutions as the evaluation criteria to reflect the relative advantages and disadvantages of the evaluation object. It is a relatively objective evaluation method.

\subsection{Evaluation matrix standardized}

For the 12 cities and 25 indexes that need to be evaluated, the initial evaluation index matrix is established: $\left(X_{i j}\right) 12 \times 25$

The normalized matrix is obtained by dimensionless transformation of index data:

$$
Y_{i j}=X_{i j} / \sqrt{\sum_{i=1}^{12} X_{i j}^{2}}, i=1,2, \cdots, 12 ; j=1,2, \cdots, 25
$$

$X_{i j}$ represents the initial value of the jth index in the ith city, $Y_{i j}$ is the normalized value of the jth index ith city. If there is a reverse index in the index system, it needs to be normalized.

\subsection{Calculate the entropy weight of each index}

Calculate the contribution degree of the jth index in the ith city:

$$
\theta_{i j}=Y_{i j} / \sum_{i=1}^{12} Y_{i j}, i=1,2, \cdots, 12 ; j=1,2, \cdots, 25
$$

Calculate the information entropy of the jth index:

$$
\begin{gathered}
H_{j}=(-1 / \ln (12)) \sum_{i=1}^{12} \theta_{i j} \ln \left(\theta_{i j}\right), j=1,2, \cdots, 25 \\
\text { If } \theta_{i j}=0 \text {, define } \theta_{i j} \ln \left(\theta_{i j}\right)=0
\end{gathered}
$$

According to the information entropy, the entropy weight of each index is calculated and recorded as, $W_{j}$ formula:

$$
W_{j}=\left(1-H_{j}\right) /\left(n-\sum_{j=1}^{25} H_{j}\right), j=1,2, \cdots, 25
$$

\subsection{Construct weighting matrix}

$$
P=\left(\begin{array}{cccc}
W_{1} Y_{1,1} & W_{2} Y_{1,2} & \cdots & W_{25} Y_{1,25} \\
W_{1} Y_{2,1} & W_{2} Y_{2,2} & \cdots & W_{25} Y_{2,25} \\
\vdots & \vdots & \vdots & \vdots \\
W_{1} Y_{12,1} & W_{2} Y_{12,2} & \cdots & W_{25} Y_{12,25}
\end{array}\right)=\left(P_{i j}\right)_{12 \times 25}
$$

$P_{i j}$ represents the normalized value of the jth index in the ith city.

\subsection{Positive and negative ideal solutions}

According to the decision weighting matrix, the optimal value and the worst value of each index in the weighting matrix are respectively taken $S^{+}$and $S^{-}$as positive ideal value and negative ideal value.

$$
\begin{aligned}
& S^{+}=\left\{\max _{1 \leq j \leq 25} S_{i j} \mid j=1,2, \cdots, 25\right\}=\left\{S_{1}^{+}, S_{2}^{+}, \cdots, S_{25}^{+}\right\} \\
& S^{-}=\left\{\min _{1 \leq j \leq 25} S_{i j} \mid j=1,2, \cdots, 25\right\}=\left\{S_{1}^{-}, S_{2}^{-}, \cdots, S_{25}^{-}\right\}
\end{aligned}
$$

\subsection{Calculating the distance of ideal solution}

There are many distance methods for positive and negative ideal solutions. In this paper, Euclidean distance is used to calculate. Let $D_{i}^{+}$denote the distance between jth index and $S^{\star}, D_{i}^{-}$denote the distance between the jth index and $S^{-}$.

$$
\begin{gathered}
D_{i}^{+}=\sqrt{\sum_{j=1}^{25}\left(S_{j}^{+}-P_{i j}^{+}\right)^{2}}, i=1,2, \cdots, 12 ; j=1,2, \cdots, 25 \\
D_{i}^{+}=\sqrt{\sum_{j=1}^{25}\left(S_{j}^{+}-P_{i j}^{+}\right)^{2}}, i=1,2, \cdots, 12 ; j=1,2, \cdots, 25
\end{gathered}
$$

\subsection{A.Calculate close degree}

Let $D_{i}$ denotes the degree to which the Kangyang of the ith city is relatively close to the optimal level, which is called close degree, and the value range is 0 to 1 . The larger $D_{i}$ is, the higher the degree of Kangyang of the object is; The smaller it is, the lower $D_{i}$ the less Kangyang suitableness of the object is. Finally, cities can be ranked according to the $D_{i}$.

$$
D_{i}=\frac{D_{i}^{-}}{D_{i}^{-}+D_{i}^{+}}, i=1,2, \cdots, 12
$$

\section{Empiricl research}

\subsection{Data sources}

According to the indicators in Table 1, the data of 12 prefecture level cities in Heilongjiang Province in 2018 are selected. The data are from China Urban Statistical Yearbook 2019, Heilongjiang Statistical Yearbook 2019, China Health Statistical Yearbook 2019, NCDC, China Air Quality Online Monitoring and Analysis Platform, 2345 Weather Network, etc. Through comprehensive treatment and calculation, the actual use value of each index is obtained.

\subsection{Model calculation}

According to the formula (1) to formula (4), the normalized matrix and the information entropy and weight of 25 secondary indicators under the suitability of Kangyang were obtained. According to formula (5), the weighted decision matrix is constructed. By using formula 
(6) to formula (9), the positive and negative ideal solutions of the evaluation index system and the distance between cities and positive and negative ideal solutions are obtained.Finally, the close degree between the evaluation object and the optimal level is calculated by formula (10), and the comprehensive ranking of 12 cities in Table 2 is obtained, and the ranking is arranged in descending order. Among them, the calculation method of ecological construction, humanistic construction, people's livelihood construction and medical construction is consistent with the suitability of Kangyang, which can be obtained only from the new calculation weight and the construction of weighting matrix.

Table2. Ranking of Kangyang suitability of Heilongjiang province in 2018

\begin{tabular}{|c|c|c|c|c|c|c|c|c|c|c|}
\hline \multirow{2}{*}{ City } & \multicolumn{2}{|c|}{$\begin{array}{c}\text { Ecological } \\
\text { construction }\end{array}$} & \multicolumn{2}{c|}{$\begin{array}{c}\text { Humanistic } \\
\text { construction }\end{array}$} & \multicolumn{2}{c|}{$\begin{array}{c}\text { Construction of } \\
\text { people's } \\
\text { livelihood }\end{array}$} & \multicolumn{2}{c|}{$\begin{array}{c}\text { Medical } \\
\text { construction }\end{array}$} & \multicolumn{2}{c|}{$\begin{array}{c}\text { Suitability of } \\
\text { Kangyang }\end{array}$} \\
\cline { 2 - 12 } & $S_{i}$ & Ranking & $S_{i}$ & Ranking & $S_{i}$ & Ranking & $S_{i}$ & Ranking & $S_{i}$ & Ranking \\
\hline Yichun & 0.891 & 1 & 0.799 & 1 & 0.292 & 4 & 0.568 & 8 & 0.589 & 1 \\
\hline Harbin & 0.181 & 10 & 0.161 & 8 & 0.790 & 1 & 0.695 & 5 & 0.446 & 2 \\
\hline Heihe & 0.629 & 2 & 0.281 & 2 & 0.180 & 8 & 0.552 & 10 & 0.381 & 3 \\
\hline Daqing & 0.384 & 4 & 0.200 & 5 & 0.430 & 2 & 0.765 & 2 & 0.350 & 4 \\
\hline Mudanjiang & 0.440 & 3 & 0.216 & 4 & 0.292 & 3 & 0.645 & 6 & 0.302 & 5 \\
\hline Hegang & 0.350 & 5 & 0.224 & 3 & 0.265 & 5 & 0.939 & 1 & 0.274 & 6 \\
\hline Qitaihe & 0.306 & 6 & 0.150 & 10 & 0.239 & 6 & 0.561 & 9 & 0.232 & 7 \\
\hline Jixi & 0.231 & 7 & 0.151 & 9 & 0.206 & 7 & 0.698 & 4 & 0.194 & 8 \\
\hline Shuangyashan & 0.215 & 8 & 0.181 & 7 & 0.142 & 9 & 0.607 & 7 & 0.178 & 9 \\
\hline Jiamusi & 0.202 & 9 & 0.188 & 6 & 0.131 & 10 & 0.731 & 3 & 0.174 & 10 \\
\hline Qiqihar & 0.110 & 11 & 0.101 & 11 & 0.127 & 11 & 0.371 & 11 & 0.115 & 11 \\
\hline Suihua & 0.055 & 12 & 0.076 & 12 & 0.076 & 12 & 0.005 & 12 & 0.072 & 12 \\
\hline
\end{tabular}

\subsection{Result analysis}

On the whole, Yichun ranked the best in the Kangyang suitability of Heilongjiang Province, and Suihua was the most unsuitable. Yichun and Heihe rank at the top of the two basic indexes of ecological construction and cultural construction, indicating that they have favorable natural and cultural environment, suitable for people to pay attention to the purpose of improving health status and humanistic needs, and meet the pursuit of both physical and spiritual levels. But at the same time, its ranking in medical construction is relatively low, indicating that the two are not suitable for the long-term stay with medical needs. Harbin ranks second in terms of comprehensive ranking. Although the ecological and cultural construction is not as good as that of most cities, the construction of people's livelihood is the best, and the medical treatment also reaches the upper middle level. For the groups who need these aspects, they can choose Harbin for Kangyang. Daqing, Mudanjiang, Hegang three cities in the index ranking are relatively high, and each has its own strengths. For example, the close Daqing urban construction and medical construction is better; Mudanjiang has good performance in ecological construction and people's livelihood construction; Hegang ranks prominently in medical construction indicators. The comprehensive ranking of Qitaihe, Jixi, Shuangyashan and Jiamusi is lower than the middle. Except for medical construction, Jixi and Jiamusi rank better, and the four cities rank relatively lower in other indicators, especially the cultural construction of Qitaihe and Jixi, the ecological construction and people's livelihood construction of Shuangyashan and Jiamusi. Qiqihar and Suihua rank at the bottom of each index, which indexes that the two cities need to strengthen the construction of all parties, find their own shortcomings that can be improved rapidly and build them, so as to meet the suitability of Kangyang.

From the perspective of ecological construction, Yichun, Heihe and Mudanjiang rank at the top, which indicates that the natural environment of these three cities is better, and Kangyang is vigorously promoted. Harbin and Jiamusi are relatively weak in attracting people through superior natural conditions. From the perspective of cultural construction, Yichun, Heihe and Hegang have obvious advantages, while Qitaihe and Jixi have insufficient construction in this respect. From the perspective of people's livelihood construction, the construction of Harbin, Daqing and Mudanjiang is at the forefront, while Shuangyashan and Jiamusi are relatively low; from the perspective of medical construction, medical security in Hegang, Daqing and Jiamusi is relatively comprehensive, while Heihe and Qitaihe need to strengthen the construction in this respect. Qiqihar and Suihua are at the end of these four aspects, and have no comparative advantage.

\section{Conclusion and suggestion}

Based on the analysis and reference of relevant research, this paper constructs the evaluation system of urban Kangyang suitability, which includes four aspects. Entropy weight - TOPSIS is a quantitative analysis method which is conducive to ignore the subjective influence, and can evaluate the urban Kangyang 
suitability more objectively. The empirical results show that Yichun and Harbin are more suitable for the groups with Kangyang needs in Heilongjiang Province at this own merits, ecological and cultural construction of Yichun city ranks first, people's livelihood conditions of Harbin city are better, and Hegang is more prominent in medical. In the research of Kangyang, on the basis of previous research, this paper adds the humanistic construction index which represents the spiritual needs, but the method used is relatively simple and needs to be further improved to find a more practical, scientific and practical evaluation method.

According to the above research results, in order to meet the different pension needs of the elderly groups and improve the development quality of Kangyang in various cities, the following suggestions are put forward: according to the ranking of ecology, humanities, people's livelihood and medical construction, consumers can choose cities that meet their own needs. For all cities with better construction, we should continue to optimize and develop. For the city after ranking we should find indexes that conform to the characteristics of our city construction and develop vigorously. For example, Jiamusi should continue to develop its medical construction and build it into a medical city to promote its economic development and achieve a virtuous circle. In the new era, Kangyang pays attention to the spiritual and emotional needs. Therefore, strengthening the humanistic construction and making it the characteristic service of Heilongjiang Province is conducive to the construction of the Kangyang service system of the whole province and driving the economic development of various cities.

\section{Acknowledgments}

This work is supported by the Philosophy and Social Science Plan Project of Heilongjiang Province under Grant 18ZK053. stage; Qiqihar and Suihua are relatively backward in the ranking of various indicators, and need to strengthen construction in many aspects; urban construction has its

\section{References}

1. Li Xiuyun, Li Junjie, Kang Liying. Evaluation of Beijing Tianjin Hebei forest Kangyang base based on eight factor model and Chengde strategy [J]. Economic research reference, 2017 (47): 71-79.

2. Tan Yimin, Zhang Zhiqiang. Study on the planning and design of forest Kangyang [J]. Journal of Hunan University of technology, 2017,31 (01): 1-9.

3. Dai Juncheng, Zhou Shangyi, Zhao Baohua, Liu Xin. Discussion on the evaluation index system of livable cities for the elderly in China [J]. Chinese Journal of Gerontology, 2011,31 (20): 4008-4013.

4. Li Jiren, $\mathrm{Xu}$ Dong. Study on the construction of evaluation index system of forest Kangyang [J]. Forestry economy, 2018,40 (03): 28-34.

5. Wang Yirun, Jin Xin, Yang Kaijun. Research review on suitability evaluation index system of China's Kangyang industry development and construction [J]. Modern commerce, 2019 (15): 10-11.

6. Yuan Fengchao. Study on regional differences of suitability of pension real estate development in North China [J]. China land science, 2013,27 (05): 85-91.

7. Pan Yangliu, Zeng Jin, Wenye, Yan Qi, Liu Yuanqiu. Study on suitability evaluation index system of forest Kangyang construction $[\mathrm{J}]$. Forestry resource management, 2017 (05): 101-107.

8. Li Suhong, Fang Jie, Yuan song. Suitability evaluation of urban pension real estate development based on social network analysis [J]. Management modernization, 2017,37 (05): 20-24.

9. Shen Qin, Yun Zhuomin. Analysis on the construction path of cultural pension service system in the new era [J]. Guangxi Social Sciences, 2019 (08): 72-77. 